\title{
An empirical study on research materials among colleague students
}

\author{
Mohsen Mardani ${ }^{a^{*}}$, Amir Mehdiabadi ${ }^{\mathrm{b}}$ and Mosayeb Karami ${ }^{\mathrm{c}}$
}

\section{Article history:} \\ Received December 25, 2011 \\ Received in Revised form \\ March, 25, 2012 \\ Accepted 28 April 2012 \\ Available online \\ May 12012 \\ Keywords: \\ Study \\ Research \\ Student
}

${ }^{a}$ Member of Young Researchers Club, MA of Islamic Azad University, Iran

${ }^{b}$ Member of Young Researchers Club, MA of Islamic Azad University, Iran

'Industrial Management of MA at Islamic Azad University, Semnan, Iran

ART I CLEINFO ABSTRACT

\begin{abstract}
The goal of the present research is to identify appropriate methods for developing a study among students who attend educational department for different universities located in city of Tehran, Iran. We study different factors influencing students on development of methods for their studies. The primary method of research is questionnaire and its reliability identified by use of Cronbach's alpha, calculated as 0.905 and its validity defined by content method. To analyze information we use deductive statistical, t-student and ANOVA tests using SPSS 19 software. Results show that management and education of school based on development of methods for study and research is not function of gender, the education of level, and their field of study and it only follows their place of service. The results also indicate that student's conditions of study about their course are proper while their condition about the pleasure study and research is not favorable.
\end{abstract}

(c) 2012 Growing Science Ltd. All rights reserved.

\section{Introduction}

Research and study are two examples of necessary and principle of information explosion era. In addition, these two processes are among important objectives of education system in each society. According to new theories of learning-teaching approaches, it is necessary for teachers to adopt an approach, which help learners become active (Kocak, 2008; Artut, 2009). Based on this approach, since there is a limitation on transition materials from teacher to learner, there is not a pure information transition and the learner is encouraged to attempt to search the information. In other words, in this learning-teaching approach, the learner is researcher. Searching and generally, investigating of the learner causes include the learner at the knowledge field who does not depend on the teacher and searches more and deeper materials volume. Searching processes are affected by various factors and identifying the factors, which are effective on studying and searching and providing them for the society youth and infant generation have been a tremendous research field.

* Corresponding author.

E-mail addresses: mmardani55@yahoo.com (M. Mardani) 
Saka and Kumas (2009) presented an example of movement of vertical shooting for implementation of problem based learning in cooperative learning groups. Oortwijn et al. (2008) presented a survey to help behavior during cooperative learning and learning gains. The survey was focused on the role of the teacher and of pupils` prior knowledge and ethnic background. Gillies and Boyle (2008) investigated teachers' discourse during cooperative learning and their perceptions of this pedagogical practice and studied teacher`s reflections on cooperative learning in other work (Gillies \& Boyle, 2010). Guneysu and Tekmen (2010) presented a method for implementing an alternative cooperative learning method. Bruneel et al. (2010) performed an investigation to reveal the nature of the barriers to collaborations between universities and industry, exploring impact of various methods in lowering barriers associated with the orientation of universities and to the relationships involved in working with university partners. They performed a large-scale survey to explore the impacts of collaboration experience, breadth of interaction, and inter-organizational trust on lowering various types of barriers. The analysis indicated that prior experience of collaborative research reduces orientation-related obstacles and that bigger levels of trust reduce all types of barriers. They claimed that breadth of interaction reduces the orientation-related, but increases transaction-related barriers.

Using a standard survey instrument, the barrier Scales, Kim (2005) surveyed university librarians' perceptions of barriers to bigger use of library and information research utilization in Seoul, Korea. The biggest obstacle was that the implications of research for practice were not clear. The other reasons were the lack of replication of the research, and shortage of time on the job to use new ideas. The other major barriers were incomprehensible English research reports and statistical analyses. The survey compared the responses of Korean librarians to similar studies of nursing professionals for cross validation and provided some comments for overcoming barriers to implementing research.

Hamidi et al. (2011) study barriers of using learning resources among Iranian university students and instructors by using a sample of fifty university instructors and 300 students who were randomly chosen from university students and instructors of Kermanshah Azad University. The results indicated that there was a substantial difference between learning resources students and instructors used and the printed resources maintained the highest frequency of implementation among the sample, and the audio-visual tools had the lowest frequency of use.

Tan et al. (2012) determined the barriers to the implementation of nursing research findings, as perceived by the nurses working in the Eastern Anatolian Region of Turkey during the year of 2009. They performed a cross-sectional design by randomly choosing 13 hospitals and encompassing general hospitals in all cities of this region. They concluded that the most important perceived by the nurses was "insufficient time on the job to implement new ideas". The average point of overall scale was found to be $68.38 \pm$ 14.66. Lozano (2006) focused on sustainable development (SD) incorporation and institutionalization into universities and the process was bound to face resistance from inside and outside stakeholders. Lozano (2006) studied various methods to overcome this resistance and presented the types of conflicts, which could arise and the role of the campus SD champion in preventing or solving them.

\section{The proposed method}

In this paper, we specify some methods at the students from the schools teaching and managing staff's view of Tehran province townships Education. Research partial objective include: 
- $\quad$ Specifying the research and study development methods at the student from the schools teaching and managing staff's view of Tehran province townships education in term of the schools staff's gender, working record, education, and education major.

- Specifying the research and study development methods at the students from the schools teaching and managing staff's view of Tehran province townships education in term of the student's family's economic state, education point, education major, age, and gender.

- Specifying the research and study development methods difficulties at the students based on the schools teaching and managing staff's view.

- $\quad$ Specifying the remedies for improving the students' research and study difficulties from the schools teaching and managing staff's view.

The following questions are investigated for the proposed study of this paper,

1- What are the research and study development methods for the students from the schools teaching and managing staff's view of Tehran province townships Education?

2- Are the research and study development methods at the students presented by the schools teaching and managing staff of Tehran province township Education, subject of the schools staffs' gender, working record, education level, and education major?

3- What are the research and development methods difficulties at the students based on the schools teaching and managing staff's view?

4- What are the students' research and study difficulties improving remedies from the schools teaching and managing staff's view?

With research to this fact that at the present research, by using the schools assistant directors, managers and teachers views other than services forces, the research and teaching development methods at the students were identified. Therefore, descriptive research method is from field finding kind. Statistical society of this research includes the entire student of Tehran province townships Education organization who were studying during the years of 2010-2011 at Tehran province townships educational schools, constituted the present research statistic society. With respect to this fact that at the measuring studies, minimum sample group volume for each sub-group is 100 subjects. In the present research, the sample volume was 133 subjects.

Sampling method at the present research is multi-stage cluster. For this purpose, at the first, among towns, covered by Tehran province townships education, 6 towns were selected. In this manner, Karaj, Eslamshahr, Robat-karim, Shahryar, Shahre-Rey and Damavand towns were randomly selected. Then, among elementary, guidance and high schools of each town, 10 schools were also randomly selected. At the final stage, from each item, 3 subjects were randomly selected among the school staff including the manager, teachers, and assistant directors. Finally, 133 subjects of the schools staff were examined at the sample group.

Research tools included the researcher-made questionnaire for measuring the research and study development methods at the students. The questionnaire sustainability was estimated 0.905 using Cronbach's alpha method. The validity of questionnaire was specified using the content validity method. On the other hand, the questionnaire was presented to the professors of training psychology field and they confirmed the methods. Information arises from executing the questionnaire includes the sample demographic information studied. In addition, the sample group opinions about the 
research and study development methods have been collected at the appendix; completely agree, completely disagree. Finally, the research and study difficulties at the students and the research and study development methods, attained from responding the sample group to the free-answered question will be collected and will be analyzed.

For describing the sample demographic information examined, the descriptive statistic methods have been used including mean, standard deviation and graph. In addition, for responding to research questions, t-test deduction statistic methods and variance analysis tests and re- experiment tests have been used.

\section{Findings}

Sample percentile frequency distribution, examined in term of the gender, town and education documents are presented in Table 1.

Table 1

Sample percentile frequency distribution examined in term of gender

\begin{tabular}{ccccc}
\hline Gender & Man & Woman & No-response & Total \\
\hline Frequency & 57 & 70 & 6 & 133 \\
$\%$ & 42.9 & 52.6 & 4.5 & 100 \\
\hline
\end{tabular}

Table 2

Sample percentile frequency distribution examined in term of Tehran province Education organization townships

\begin{tabular}{cccccccc}
\hline Town & Karaj & Eslamshahr & Robat-karim & Shahryar & Shahre-Rey & Damavand & Total \\
\hline Frequency & 11 & 40 & 17 & 17 & 36 & 12 & 133 \\
$\%$ & 8.3 & 30 & 12.8 & 12.8 & 27.1 & 9 & 100 \\
\hline
\end{tabular}

Table 3

Sample percentile frequency distribution examined in term of the education

\begin{tabular}{ccccccc}
\hline Year of Education & 12 & 14 & 16 & 18 & No response & Total \\
\hline Frequency & 12 & 40 & 66 & 10 & 5 & 133 \\
$\%$ & 9 & 30.1 & 49.6 & 7.5 & 3.8 & 100 \\
\hline
\end{tabular}

\subsection{First question: what kind of research and study development methods do students have in terms of} schools teachers and managing staff's point of view?

The research and study development methods at the students from Tehran province townships Education organization teaching and managing staff's view are as below:

1-Teaching the research and study methods to the students directly, 2- presence of the research counselors at schools, 3- presence of the teaching counselors at schools, 4- Existence of the suitable context at schools, 5- promoting the co-operation sprit among the students, 6- Existence of the equipped library at schools, 7- Increasing the teaching abilities, 8- Increasing the teachers' research, 9- Increasing the parents' abilities to study, 10- Preventing from any ranking among students, 11Preparing the research and study culture at school, 12- Hobbling the book-reading matches, 13- Using the students opinions, 14- Using the parents' opinions, 15- Using the school staffs' opinions, 16Material encouraging the students, 17- Non-material encouraging the students, 18- Not-punishing the students, 19- Establishing the book exhibitions in the schools, 20- Building competition among the students, 21- Existence of student thought chamber at the school, region and country levels, 22- 
Providing the welfare facilities for the staffs who work at school, 22- Providing job security for the school workers, 23- Holding the scientific tours inside the country, 24- Holding the scientific tours outside the country, 25- Financial supports from the teachers (research grants), 26- creating the positive attitude towards the research and study among the students, 27- Executing the active and new teaching methods by the teachers, 28- Teaching the research and study methods for the parents, 29Teaching the study and research methods to the teachers and the students by the university professors , 30- Existence of the equipped laboratory in the school, 31- Holding the research matches, 32Holding the student seminars at the school, region and country levels, 32- Presence of the research assistance in the education organizations and schools, 33-Existence of the student cultural, research and teaching magazines, 34- Interacting (relating and co-operating) the schools with the universities , 35-Co-operating the university professors with the elite students for conducting the common (joint) researches , 36- Transferring the student responsibilities such as training, researching, and teaching assistance, 37- Interacting (relating and co-operating) the schools with the productive, service and commercial centers , 38-Enjoying the parents from the high education, 39- High family economic state.

3.2 Second question: Are the research and study development methods at the students presented by the school teaching and managing staff of Tehran province townships education, subject of the school workers gender, education level, education major, and service place town?

The results of our survey in terms of gender have been summarized in Table 4 and Table 5.

Table 4

Mean and standard deviation of the sample opinions examined in term of gender

\begin{tabular}{ccc}
\hline Gender & Average & Standard Deviations \\
\hline Men & 149.40 & 15.409 \\
Women & 144.61 & 30.660 \\
\hline
\end{tabular}

Table 5

T-test for comparing the men and women's view

\begin{tabular}{ccccc}
\hline & Levene Test & \multicolumn{2}{c}{ T Test } \\
\hline $\mathrm{F}$ & Significant level & $\mathrm{t}$ & Degrees of freedom & Significant level \\
13.3 & 0.000 & 1.074 & 125 & 0.285 \\
\hline & & 1.142 & 105.89 & 0.256 \\
\hline
\end{tabular}

As we can observe, the independent t-test and the results show that there is not a significant difference among the variables, statistically.

\section{Table 6}

uni-directional variance analysis tests for comparing the sample group opinions

(views) examined in term of the education document

\begin{tabular}{cccccc}
\hline $\begin{array}{c}\text { education } \\
\text { document }\end{array}$ & Sum of Squares & $\begin{array}{c}\text { Degrees of } \\
\text { freedom }\end{array}$ & Mean Square & F & Significant level \\
\hline Between Groups & 634.991 & 3 & 211.664 & .351 & .789 \\
Within Groups & 74839.689 & 124 & 603.546 & & \\
\hline Total & 21558.430 & 127 & & & \\
\hline
\end{tabular}


Again, we by comparing the sample opinions mean examined, in term of the education major, using the uni-directional variance analysis we can observe that there is not a significant different among the means, statistically.

\section{Table 7}

uni-directional variance analysis test for comparing the sample group opinions examined in term of the service place town

\begin{tabular}{cccccc}
\hline Education document & $\begin{array}{c}\text { Sum of } \\
\text { Squares }\end{array}$ & Degrees of freedom & Mean Square & F & Significant level \\
\hline Between Groups & 12114.570 & 22 & 550.662 & .840 & .670 \\
Within Groups & 66885.398 & 102 & 655.739 & & \\
\hline Total & 78999.968 & 124 & & & \\
\hline
\end{tabular}

The results of Table 7 compare the sample opinions mean examined in term of the service place town. It uses uni-directional variance analysis and the results show that there is a significant difference among means, statistically.

\section{Table 8}

uni-directional variance analysis test for comparing the sample group opinions examined in term of the service place town

\begin{tabular}{cccccc}
\hline education document & $\begin{array}{c}\text { Sum of } \\
\text { Squares }\end{array}$ & $\begin{array}{c}\text { Degrees of } \\
\text { freedom }\end{array}$ & Mean Square & F & Significant level \\
\hline Between Groups & 37119.500 & 5 & 7423.900 & 18.166 & 0.000 \\
Within Groups & 51900.170 & 127 & 408.663 & & \\
\hline Total & 89019.669 & 132 & & & \\
\hline
\end{tabular}

Variance analysis test results significance indicating that there is a significant difference, at least, between one pair of means. For specifying the difference between the given doubled mean, Toki pursuance test was used. The results of Toki sub-experiment test for comparing in term of the education document have been presented in Table 9.

Table 9

Toki sub-experiment test for comparing the sample group opinions examined in term of the service place town

\begin{tabular}{|c|c|c|c|c|c|c|}
\hline \multicolumn{2}{|c|}{ Service place town } & \multirow{2}{*}{$\begin{array}{c}\text { Mean } \\
\text { Difference }\end{array}$} & \multirow[t]{3}{*}{ Std.Error } & \multirow{3}{*}{$\begin{array}{l}\text { Significant } \\
\text { level }\end{array}$} & \multicolumn{2}{|c|}{ 95\% confidence Interval } \\
\hline & & & & & Inower & Inner \\
\hline \multirow{6}{*}{ Karaj } & & & & & & \\
\hline & EslamShahr & 8.450 & 6.882 & .822 & 11.47 & 28.37 \\
\hline & RobatKarim & *52.822 & 7.822 & 0.00 & 30.19 & 75.46 \\
\hline & Shariar & -6.647 & 7.822 & .957 & -29.28 & 15.99 \\
\hline & Shahrerey & 12.500 & 6.964 & .473 & -7.65 & 32.65 \\
\hline & Damavand & 3.917 & 8.438 & .997 & -20.50 & 28.33 \\
\hline \multirow{4}{*}{ EslamShahr } & RobatKarim & $44.374^{*}$ & 5.853 & 0.000 & 27.44 & 61.31 \\
\hline & Shariar & -15.097 & 5.853 & .110 & -32.03 & 1.84 \\
\hline & Shahrerey & 4.050 & 4.644 & .952 & -9.39 & 17.49 \\
\hline & Damavand & -4.533 & 6.654 & .984 & -2379 & 14.72 \\
\hline \multirow{5}{*}{ RobatKarim } & Shariar & $-59.471^{*}$ & 6.934 & 0.000 & -79.54 & -39.41 \\
\hline & Shahrerey & $-40.324 *$ & 5.949 & 0.000 & -5754 & -23.11 \\
\hline & Damavand & $-48.907 *$ & 7.622 & 0.000 & -70.96 & -26.85 \\
\hline & Shahrerey & $19.147^{*}$ & 5.949 & 0.020 & 1.93 & 36.36 \\
\hline & Damavand & 10.564 & 7.622 & .735 & -11.49 & 32.62 \\
\hline Shahrerey & Damavand & -8.583 & 6.738 & .799 & -28.08 & 10.92 \\
\hline
\end{tabular}


As we can observe from the results of Table 9, there is a significant difference between Karaj and Robat-karim, Eslam-shahr and Robat-karim, Robat-Karim and Shahryar, Robat-Karim and Shahr-eRey, Robat-Karimnand, Damavand and Sharyar and Shahr-e-Rey.

3.3 Thirst question: what are the research and study development methods' barriers for students at schools in terms of teaching and managing staffs' point of view?

To specify the students difficulties set about the research and study development methods, the following questions are presented.

1- Reluctance of the family in the study and research,

2- Inappropriate planning the education about the research and study in the students and all of the education workers,

3- Lack of the study resources,

4- Expensive study resources,

5- Insufficient time spent by teachers,

6- Insufficient research context to study at schools,

7- Absence the necessary guide provided by professors at the education,

8- Lack of a good cooperation among students for team work,

9- Shortage of the research and study facilities,

10- Lack of information about the research methods for both teachers and the students,

11- Lack of a good awareness,

12- Insufficient while-serving trainings,

13- Low information on internet and computer facilities among the education staff, teachers and students,

14- Incorrect guidance among the students by the school teachers and managing staffs,

15- Lack of a good culture of research among the society,

16- Lack of a good awareness on the importance of research and its positive effects on human being,

17- Undesirable teaching methods,

18- Unsuitable friends,

19- Lack of a clear perception on the research,

20- Lack of a good education among parents,

21- Lack of a good motivation among students,

22- Lack of a sufficient financial support,

23- Absence of a text-book named the research and study methods from the elementary point,

24- Economic problems of the students,

25- Lack of support from the research at the society,

26- Insufficient relationships between the text-books with non-text-books,

27- Weakness of the education assessment based on the research,

28- Absence of the research assistance at schools,

29- Lack of information and recognition of the schools' representatives in the research activities,

30- Lack of a good research from elementary schools,

31- Concentrating the schools on the text-books,

32-Absence of the project text-book at schools,

33- Absence of up-date resources at schools,

34- Absence of the newspaper at schools, 
35- Insufficient holding the book-reading matches at schools,

36- Insufficiency of the attractive scientific books amount,

37- Lack of a good support on behalf of parents and schools.

38-Staffs for the research- and study- seeking students

3.4 Fourth question: What are the students' research and study problems improvement remedies from the school teaching and managing staff's view?

For specifying the students research and study problems improvement remedies set, one descriptive question was arisen. At the below, the sample group responses set to this question are presented.

1- Interviewing with the successful researchers and identifying their success and presenting to the students,

2- Holding the research method teachings for the teachers and students,

3- Providing the research and study culture by the media,

4- Updating teachers' research capabilities,

5- Encouraging the students to study and research,

6- Providing the necessary possibilities including increasing the books, magazines, computer and internet,

7- Providing suitable context to study and research,

8- Existence of the interaction among the university professors, teachers and parents,

9- Assigning more scores for research activities,

10- Allocating a lesson to the research and study at the schools

11- Increasing the schools budget,

12- Holding the book-reading sessions in the schools and allocating a scare for the students' book-reading,

13- Introducing the attractive books by the schools teachers, staff and assistance directors,

14- Printing the attractive and scientific books,

15- Allocating a bonus for the students to purchase the books,

16- Presenting a good guidelines for teachers and researchers to study at schools,

17- Using the modern and active teaching methods by teachers,

18- Using the experienced professors for while service teaching

19- Increasing the schools teaching and aid teaching means.

General assessment of the student's textbook materials study state based on the schools Teaching and managing staff's view are summarized in Table 10.

Table 10

Results of general assessment of students' textbook materials study state based on the sample group view

\begin{tabular}{cccccccc}
\hline Items & Very High & High & Medium & Low & Very Low & Unknown & Total \\
\hline Frequency & 0 & 18 & 49 & 39 & 11 & 17 & 133 \\
$\%$ & 0 & 12.8 & 36.8 & 29.3 & 8.4 & 12.8 & 100 \\
\hline
\end{tabular}

Table 11

General assessment results of the students' non-textbook materials study state based on the sample group view

\begin{tabular}{cccccccc}
\hline Items & Very High & High & Medium & Low & Very Low & Unknown & Total \\
\hline Frequency & 0 & 10 & 25 & 64 & 17 & 17 & 133 \\
$\%$ & 0 & 7.5 & 18 & 48.9 & 12.8 & 12.8 & 100 \\
\hline
\end{tabular}


Table 12

General assessment result of the research state at the students based on the sample group view

\begin{tabular}{cccccccc}
\hline Items & Very High & High & Medium & Low & Very Low & Unknown & Total \\
\hline Frequency & 0 & 7 & 19 & 64 & 25 & 18 & 133 \\
$\%$ & 0 & 5.3 & 14.3 & 48.1 & 18.8 & 13.5 & 100 \\
\hline
\end{tabular}

As we can observe from the results of Table 10, over $50 \%$ of the surveyed students believed that there did not have the access to good quality textbooks and only $12.8 \%$ of the students were completely satisfied on the quality of the textbook materials. Nearly, 75\% of the survey people believed that nontextbook materials are not interesting and according to the results of Table 10 and Table 11, no one believed that the quality of textbook materials was good. Table 12 also shows that most students did not like the research state.

\section{Discussion and Conclusion}

In this paper, we have presented an empirical study on two important functions of the education and we explained the relative importance to develop these two functions for students. We have explained that students could be more productive when they have the access to better environmental and equipment facilities. Therefore, the research aimed to identify the research and study development methods among students who were attending different universities in Tehran province. Based on the present research results, the research and study, some important development methods were detected. In summary, it seems that students' textbook materials were considered as relatively in undesirable conditions; the students' non-textbook materials were also unattractive and the research physical conditions were also considered to be undesirable for undergraduate or graduate students. Based on the results of this study we recommend to perform the research for other societies and among wider population to reach solutions that are more realistic.

\section{References}

Artut, P. D. (2009). Experimental evaluation of the effects of cooperative learning on Kindergarten children`s mathematics ability. International Journal of Educational Research, 48, 370- 380.

Bruneel, J., D’Este, P., \& Salter, A. (2010). Investigating the factors that diminish the barriers to university-industry collaboration. Research Policy, 39(7), 858-868.

Gillies, R. M., \& Boyle, M. (2010). Teacher`s reflections on cooperative learning: Issues of Implementation. Teaching and Teacher Education, 26, 933- 940.

Gillies, R. M., \& Boyle, M. (2008). Teachers' discourse during cooperative learning and their perceptions of this pedagogical practice. Teaching and Teacher Education, 24, 1333-1348.

Guneysu, S., \& Tekmen, B. (2010). Implementing an alternative cooperative learning method. Procedia Social and Behavioral Sciences, 2, 5670- 5676.

Kocak, R. (2008). The effects of cooperative learning on psychological and social traits among undergraduates students. Social Behavior and Personality, 36(6), 771-82.

Kim, K. (2005). Perceived barriers to research utilization by Korean university librarians. The Journal of Academic Librarianship, 31(5), 438-448.

Hamidi, F., Khosravi Rostami, M., \& Rahimi, M. (2011). Comparing barriers to using learning resources among Iranian University students and instructors. Procedia Computer Science,3, 122127.

Lozano, R. (2006). Incorporation and institutionalization of SD into universities: breaking through barriers to change. Journal of Cleaner Production, 14(9-11), 787-796 
Oortwijn, M. B., \& Boekaerts, M., Vedder, P., \& Strijbos, J.-W. (2008). Helping behavior during cooperative learning and learning gains: The role of the teacher and of pupils `prior knowledge and ethnic background. Learning and Instruction, 18, 146-159.

Saka, A.Z. \& Kumas, A. (2009). Implementation of problem based learning in cooperative learning groups: An example of movement of vertical shooting. Procedia Social and Behavioral Sciences, 1, 1327- 1336.

Tan, M., Sahin, Z.A., \& Özdemir, F.K. (2012). Barriers of research utilization from the perspective of nurses in Eastern Turkey. Nursing Outlook, 60(1), 44-50. 